\title{
Correction to: Hidden Present, Visible Absent in the City of Dreams: Assembling the Collective Imagination
}

\author{
Paul Rhodes ${ }^{1}$ • Dominik Mihalits ${ }^{2}$ - Katrin Lättman ${ }^{3}$ - Natalie Rodax ${ }^{2}$ • \\ Severin Hornung ${ }^{4}$ - Anne Bryde Chistensen ${ }^{5}$. Johanna Degen ${ }^{6}$. \\ Victoria Schüttengruber $^{2} \cdot$ Martine Tchitchihé $^{7} \cdot$ Shifa Haq $^{8}$. \\ Anna-Eva Nebowsky ${ }^{9}$. Tuuli Pern ${ }^{10}$ - Ernst Schraube ${ }^{11}$ - Veronica Botelho ${ }^{12}$
}

\section{Correction to: Human Arenas https://doi.org/10.1007/s42087-018-0020-z}

The original version of this article unfortunately contained a mistake. The name of "Tuuli Pern" is now corrected in the author group of this article. The original article has been corrected.

The online version of the original article can be found at https://doi.org/10.1007/s42087-018-0020-z

\section{Paul Rhodes}

p.rhodes@sydney.edu.au

Clinical Psychology Unit, School of Psychology, University of Sydney, Sydney, Australia

2 Fakultät für Psychologie, Sigmund Freud University, Vienna, Austria

3 Service Research Center and Department of Social and Psychological Studies, Karlstad University, Karlstad, Sweden

4 Heinz College, Carnegie Mellon University, Pittsburgh, USA

5 Department of Clinical Medicine, University of Copenhagen, Copenhagen, Denmark

6 Abteilung Psychologie, Europauniversität Flensburg, Flensburg, Germany

7 Comparative Literature and Literary Theory University of Pennsylvania, Philadelphia, USA

8 School of Human Studies, Ambedkar University, Delhi, India

9 Fakultät für Sozialwissenschaft, Ruhr-Universität, Bochum, Germany

10 Department of Semiotics, University of Tartu, Tartu, Estonia

11 Department of People and Technology, Roskilde University, Roskilde, Denmark

12 Università degli studi di Firenze, Florence, Italy 